БЕЛУГИНА Надежда Борисовна - аспирант департамента политологии и массовых коммуникаций Финансового университета при Правительстве РФ (125993, Россия, г. Москва, ГСП-3, Ленинградский $n p-\kappa m, 49 ;$ belugina.nb@gmail.com)

РЯзАНОВА Лилия Вячеславовна - аспирант, ассистент департамента политологии и массовых коммуникаций Финансового университета при Правительстве РФ (1255993, Россия, г. Москва, ГСП-3, Ленинградский пр-кт, 49; liliya_ryazanova@mail.ru)

\title{
ПОЛИТИЧЕСКИЙ ДИСКУРС КАК КОММУНИКАТИВНАЯ ПРАКТИКА КОНСТРУИРОВАНИЯ ВИРТУАЛЬНОЙ ПОЛИТИЧЕСКОЙ РЕАЛЬНОСТИ
}

\begin{abstract}
Аннотация. На основе постмодернистского подхода к пониманию современности авторы выявляют условия зарождения и сущность нового явления под названием «виртуальная политическая реальность», обозначают теоретические подходы к пониманию социальных и коммуникативных практик ее конструирования. Особо подчеркивается, что указанные феномены, а также дискурсивные практики имеют знаковую природу. Политический дискурс рассматривается авторами как коммуникативная практика создания смысловых значений определенных политических явлений и действий. Авторы поднимают вопрос взаимовлияния дискурса и социальной действительности, рассматривая трансформацию политического дискурса как инструмент изменения виртуальной политической реальности.
\end{abstract}

Ключевые слова: социальные практики, коммуникативные практики, дискурс, политический дискурс, виртуальная политическая реальность

$\mathrm{H}$ астоящее мироустройство определяет постмодернистская логика организации общества. Она характеризуется принципами субсистентности, неопределенности и конструируемости реальности. В основе такого мироустройства лежит производство знаковых ценностей.

До постмодерна существовали еще две парадигмы устройства общества. Философ и политолог А.Г. Дугин выделяет парадигмы премодерна, модерна и постмодерна [Дугин 2009]. Он считает, что основой мироустройства в премодерне был сакральный мир, в модерне - реальный мир. В дальнейшем постараемся ответить на вопрос, как трансформируется представление о реальности в постмодерне.

Так, австрийский философ А. Мэйнонг еще задолго до эпохи постмодерна формулирует принцип субсистентности. Он говорит о том, что есть определенная взаимосвязь между окружающей нас материей и идеями. Существующие предметы дают нам пищу для представления о возможности существования других предметов или концепций. Одним из ярких примеров, который приводит А. Мэйнонг, является идея о существовании золотой горы. Так как в реальности существуют горы и золото, и мы можем их себе представить на уровне идей, то существует вероятность, что в реальной жизни можно увидеть и золотую гору, потому как мы можем ее себе представить. Таким образом, философ делает предположение, что реальность вероятна, и мы не можем опровергнуть существование каких-либо идей, пока не будет дано опровержение этому. Как и в случае с золотой горой, опровергнуть ее существование практически нереально, поскольку всегда есть вероятность, что такой феномен может существовать.

Из описанного выше следует, что законы реальности подменяются субсистентностью. Вместо эмпирически доказанной реальности окружающих нас предметов и явлений появляются элементы, которые существуют в мире идей, но которые могут как иметь, так и не иметь аналоги в мире вещей. Данный 
принцип субсистентности хорошо иллюстрирует эксперимент австрийского физика Э. Шредингера под названием «кот Шредингера». Ученый мысленно представил ящик, в котором находится кот, радиоактивное атомное ядро и сосуд с ядовитым газом. Эксперимент построен таким образом, что за отведенный час ядро может быть подвергнуто распаду с вероятностью 50\%. В случае распада ядра сосуд выпускает газ, и кот умирает. Соответственно, по истечении часа вероятность гибели кота составит 50\%, к концу эксперимента кот может остаться живым или умереть.

Таким образом, мы видим тенденцию, что реальность, построенная на принципах эмпирической доказательности, исчезает. На смену ей приходит текст, дискурс, виртуальная реальность и т.д. Окружающая нас действительность находится между миром идей и вещей. Этот новый сконструированный мир, употребляя терминологию А. Мэйнонга, субсистирует, т.е. он может отображать как реальные, так и искаженные или искусственно сконструированные явления. На наш взгляд, настоящее мироустройство как нельзя лучше описывает понятие «виртуальный мир», или, если быть точнее, «виртуальная реальность». Так как в рамках нашего анализа интересна в первую очередь политическая сфера общественных отношений, то в дальнейшем мы будем рассматривать более узкое проявление вышеуказанного феномена, сформулировав его название как виртуальную политическую реальность.

Далее мы обратимся к подходам, раскрывающим сущность виртуальной политической реальности. Условно их можно обозначить как пространственный, симулятивный, сетевой и символический.

Согласно теории французского социолога П. Бурдье, социальная реальность определяется совокупностью позиций, которые занимают индивидуумы. Данное пространство состоит из определенных полей, к которым ученый относил поля политики, культуры, права и т.д. В каждом из полей социального пространства присутствует четыре вида капитала: экономический, социальный, культурный и символический. В определенном поле к наибольшему успеху приводит определенный вид капитала и/или их наиболее выгодная комбинация.

В концепции П. Бурдье борьба за власть определяется как конкуренция за формирование пространства на символическом уровне, она проявляется «в состязании за монопольное право обозначать новые объекты или переименовывать существующие, субъекты используют приобретенный в предшествующей борьбе и гарантированный законом символический капитал» [Бурдье 1993: 147].

Французский социолог Ж. Бодрийяр окружающую нас действительность называет гиперреальностью и определяет ее как пространство, наполненное симулякрами. Мыслитель раскрывает понятие «симулякр» как изображение без оригинала, репрезентацию чего-то, что на самом деле не существует. Он обозначает три порядка симулякров: подделку, производство и симуляцию [Бодрийяр 2018]. Симулякры первого порядка формируются на основе системы ценностей, второго - на основе закона стоимости, симулякры третьего порядка формируются без опоры на реально существующие объекты. По сути, симулякры являются знаками, которые в той или иной степени оторваны от обозначаемого ими объекта.

Испанский социолог М. Кастельс происходящие в Интернете процессы называет реальной виртуальностью. Опираясь на теоретические концепции Р. Барта и Ж. Бодрийяра, согласно которым производство знаков лежит в основе коммуникации [Барт 1989; Бодрийяр 2013], М. Кастельс дает следующее определение реальной виртуальности - «это система, в которой сама реальность (т.е. материальное/символическое существование людей) полностью схвачена, полностью 
погружена в виртуальные образы, в выдуманный мир, мир, в котором внешние отображения находятся не просто на экране, через который передается опыт, но сами становятся опытом». Автор подчеркивает, что «в некотором смысле вся реальность воспринимается виртуально» [Кастельс 2000].

Согласно отечественным исследователям О.Ю. Малиновой, С.П. Поцелуеву, Д.Е. Москвину, Н.М. Мухарямову и др., символы играют одну из ключевых ролей в борьбе за властные ресурсы и реализацию политики [Символическая политика... 2012]. Сам термин «символическая политика» определяется «как деятельность, связанная с производством определенных способов интерпретации социальной реальности и борьбой за их доминирование» [Малинова 2012: 10]. Сильной стороной данного подхода является соединение символического аспекта общественных отношений с применением их с целью борьбы за политическую власть.

Таким образом, во всех описанных подходах к пониманию виртуальной политической реальности есть акцент на знаковой природе общественных отношений, и в качестве основных инструментов политики обозначаются символическое насилие, производство симулякров или целенаправленная деятельность по созданию знаков и символов.

Объективность политической реальности носит особый характер, она не существует без общества, воспроизводящего ее элементы в своем сознании и конкретных действиях. Конструирование виртуальной политической реальности можно представить как процесс создания смыслов, которые при идеальных условиях должны отражать реальные практики социального взаимодействия, однако зачастую являются коннотацией искусственных конструктов.

Ниже рассмотрим три базовых подхода к пониманию понятия «социальная практика». Это теории Э. Гидденса, Г. Гарнфинкеля и П. Бурдье.

Э. Гидденс, автор теории структурации, описывает социальную реальность как совокупность практик, которые ее формируют [Гидденс 2005]. Согласно данной теории, социальная реальность воспроизводится благодаря каждодневным рутинизированным практикам, а сами практики существенным образом зависят от окружающего их контекста. При этом автор особо подчеркивает, что благодаря социальным практикам повседневность постоянно воспроизводится, но не конструируется.

Г. Гарфинкель также видит природу социальных практик в рутинных действиях [Гарфинкель 2007]. По мнению ученого, большое влияние на индивида и включение его в социальные практики оказывают фоновые ожидания - определенные установки на предрасположенность к выполнению социально одобряемых действий. Фоновые ожидания определенным образом предопределяют реакцию людей на обстоятельства, однако нельзя сказать, что они полностью предопределят деятельность человека.

П. Бурдье в качестве основы социального действия видит габитус. Под термином «габитус» понимается «система прочных приобретенных предрасположенностей (диспозиций)». Габитус человека, подобно растению, формируется под воздействием внешних факторов. С одной стороны, габитус влияет на практики человека, его предрасположенность к тому или иному поведению, с другой габитус помогает человеку классифицировать различные практики общества и адекватно ориентироваться в социальной среде. Согласно П. Бурдье, благодаря социальным практикам реальность как воспроизводится, так и конструируется.

Таким образом, на основе описанных выше подходов можно сделать вывод, что социальные практики - это повторяющаяся деятельность, функционирующая на основе предрасположенностей и выработанных правил. В свою очередь коммуникативные практики являются разновидностью социальных практик, 
основанием которых является коммуникация. Благодаря им конструируется виртуальная политическая реальность.

Одной из ярких коммуникативных практик, формирующих виртуальную политическую реальность, является политический дискурс.

Все социально-политические явления детерминированы дискурсивными практиками. Понятие политического дискурса в настоящее время является дискуссионным, и его интерпретация определяется скорее решением конкретных исследовательских задач. В контексте политической коммуникации дискурс в наиболее общем виде трактуется как специфический способ взаимодействия. Т.А. ван Дейк в своих работах предложил два определения дискурса - в широком и узком смысле. Широкое определение дискурса указывает на «коммуникативное событие, происходящее между говорящим, слушающим (наблюдателем и др.) в процессе коммуникативного действия в определенном временном, пространственном и прочем контексте. Это коммуникативное действие может быть речевым, письменным, иметь вербальные и невербальные составляющие» [ван Дейк 1989: 45]. Дискурс в узком смысле, в свою очередь, включает в себя только вербальную составляющую данного коммуникативного действия, т.е. текст. В этом смысле дискурс обозначает «завершенный или продолжающийся “продукт” коммуникативного действия, его письменный или речевой результат, который интерпретируется реципиентами» [ван Дейк 1989: 46].

Вместе с тем, основываясь на позиции Ю. Хабермаса [Хабермас 2001], отметим, что современный индивид является участником общественной дискуссии, он оказывается постоянно окруженным предлагаемыми СМИ моделями социальной действительности и навязываемыми моделями поведения. Мировоззрение и потребности индивида формируются через принятие и собственную интерпретацию общественных проблем, которые транслируются путем функционирования дискурсов. Посредством дискурса человек ищет ответы на актуальные вопросы и оказывается непосредственно вовлеченным в социальную действительность.

Одним из центральных вопросов коммуникативной практики является вопрос влияния дискурса на общественные отношения и, с другой стороны, социальной действительности на формирование, трансляцию и поддержание устойчивости определенных дискурсов. Так, согласно П. Бергеру и Т. Лукману, «язык реализует мир в двояком смысле слова: он его постигает, и он его производит» [Бергер, Лукман 1995: 104]. Иными словами, картина мира непрерывно создается обществом в процессе взаимодействия людей друг с другом, и дискурс, очевидно, участвует в этом процессе как результат такого взаимодействия. С другой стороны, само по себе общение представляет собой актуализацию определенного рода дискурса, поскольку люди постоянно производят социально-политические отношения не только благодаря своим действиям, но и благодаря установленным нормам в виде определенных институтов. К коммуникационным нормам относится и языковая практика, которая направлена на воспроизводство социальной реальности на основе превалирующих дискурсов.

Дискурс - это результат коммуникативного взаимодействия, в котором его участники транслируют определенные смыслы, ценности и идеи и формируют общее смысловое поле, позволяющее понять факторы политических действий акторов коммуникации, актуальные элементы политической реальности и то, как политические акторы интерпретируют реальность. Процесс восприятия политических действий сопровождается интерпретацией информации через уже имеющийся опыт и ценностные установки в соответствии с теми фактами, которые мы считаем истинными. Таким образом, политический дискурс представляет собой коммуникативную практику создания смысловых значений в 
ходе взаимодействия людей в политическом поле, с помощью которых может быть сформулирована система интерпретации политической реальности. Однако дискурс представляет собой не весь информационный поток, а лишь внедряемую в конкретный социальный контекст информацию.

Политический язык в современных исследованиях все чаще выступает не только инструментом описания политической действительности, но и важной составляющей самих политических событий, формирующей их значения. В настоящее время наблюдается тенденция трактовки языка и как средства отражения политической реальности, и как способа ее конструирования. Современные политические парадигмы радикально трансформируются, ориентируясь в т.ч. и на существующие практики политической коммуникации. Очевидно, что дискурсивность присуща политике больше, чем другим сферам. Не случайно ряд исследователей акцентируют внимание на символичности и субъективности политики, что подразумевает дискурсивность каждого элемента политического конструирования: «политическое мышление - политическое действие - языковая форма».

Дискурс выполняет ряд функций, определяющих его влияние на процесс конструирования политической реальности:

- конструирование и деконструирование социально-политического образа мира;

- формирование социальных интересов и общественного мнения;

- индикация распределения и регулирования властных отношений;

- формирование социально-политической идентичности.

Как было определено выше, политическая реальность - это символическая реальность, наполненная смыслами и значениями, которые определяют намерения и действия политических акторов. Усвоение данных смыслов задает определенные модели поведения и отношение к данной реальности. Общество - это открытая, сложная и динамичная система, которой присуща сегментация, из-за чего дискурсы постоянно борются между собой за право придания тем или иным событиям определенных значений. Так, Э. Лакло и Ш. Муфф утверждают, что дискурсы постоянно находятся в состоянии противоборства, они конкурируют между собой за установление определенных значений [Филлипс, Йоргенсен 2008]. Исходя из этого, исследователи трактуют дискурс как открытую структуру, для которой характерно множество подобных вариантов значений. Индивид при этом является носителем определенной идентичности и как субъект помещен внутрь одного из дискурсов. Когда происходит столкновение между личностями (группами индивидов), неизбежно сталкиваются и их идентичности. При противоборстве дискурсов индивид становится перед социальным выбором, в основе которого лежит дихотомия «мы/другие». Таким образом, Э. Лакло и Ш. Муфф рассматривают политику как сферу борьбы между дискурсами.

В этом отношении трансформация дискурса означает присвоение того или иного значения социальному контексту. Так, Ю.М. Лотман указывал на наличие множества противоборствующих конструкций в общественном сознании, которые стремятся вытеснить друг друга и представлять свою интерпретацию социальной реальности [Лотман 1999].

Политический дискурс как коммуникативная практика включает в себя следующие компоненты:

1) знаковую систему, ориентированную на отражение определенных политических действий коммуникативной сферы;

2) тезаурус заданной коммуникативной сферы;

3) типичные модели речевого поведения; 
4) систему жанров политического дискурса.

В отличие от институционального, публичный медиадискурс носит символический характер, он зачастую строится на простых терминологических конструкциях, идиомах, фразеологизмах для возможности восприятия его массовой аудиторией, а не только определенными социальными группами.

Соответственно, изменяя какой-либо из компонентов дискурса, мы получаем новый вектор дискурсивной практики, что часто предполагает трансформацию дискурсивной реальности или создание новых дискурсивных практик. Процесс создания виртуальной политической реальности сопровождается применением различных лингвистических приемов и психологических методов, целью которых становятся установки и ценности индивида и социальной группы. Именно в коммуникативном процессе подобные социальные представления формируются, модифицируются, распространяются в пределах социальной группы. Таким образом, политический дискурс позволяет постоянно актуализировать в обществе представления о смысловых значениях тех или иных политических действий.

Таким образом, виртуальная реальность не является новым феноменом. В современном понимании виртуальность напрямую не соотносится с техническими средствами, ее нельзя назвать как полностью технической, так и сконструированной исключительно сознанием человека. Виртуальная политическая реальность предполагает вовлечение множества субъектов политики и их интерпретацию политических событий, действий, внедрение ценностей, символов и т.д. И в этом отношении политический дискурс, конструируемый множеством политических акторов в собственных интересах, становится источником построения социальной практики.

\section{Список литературы}

Барт Р. 1989. Избранные работы: Семиотика: Поэтика. М.: Прогресс. 616 с.

Бергер П., Лукман Т. 1995. Социальное конструирование реальности. Трактат по социологии знания. М.: Медиум. 323 с.

Бодрийяр Ж. 2013. Символический обмен и смерть. М.: Добросвет. 392 с.

Бодрийяр Ж. 2018. Симулякры и симулящии. М: Рипол Классик; Постум. 320 c.

Бурдье П. 1993. Социальное пространство и символическая власть. - THESIS. Вып. 2. С. 137-150.

Гарфинкель Г. 2007. Исследования по этнометодологии. СПб: Питер. 335 с.

Гидденс Э. 2005. Устроение общества: Очерк теории структурации. 2-е изд. М.: Академический Проект. 528 с.

Дейк Т.А., ван. 1989. Язык. Познание. Коммуникация. М.: Прогресс. 308 с.

Дугин А.Г. 2009. Постфилософия. Три парадигмы в истории мысли. М.: Евразийское движение. 744 с.

Кастельс М. 2000. Информационная эпоха: экономика, общество и культура. М.: ИД ГУ-ВШЭ. 608 с.

Лотман Ю.М. 1999. Внутри мыслящих миров. Человек- текст - семиосфера история. М.: Языки русской культуры. 464 с.

Малинова О.Ю. 2012. Символическая политика: контуры проблемного поля. Символическая политика. Вып. 1. Конструирование представлений о прошлом как властный ресурс: сборник научных трудов (научн. ред. О.Ю. Малинова). 2012. М.: ИНИОН РАН. С. 5-16.

Символическая политика. Вып. 1. Конструирование представлений о прошлом как властный ресурс: сборник научных трудов (научн. ред. О.Ю. Малинова). 2012. М.: ИНИОН РАН. 334 с. 
Филлипс Л.Дж., Йоргенсен М.В. 2008. Дискурс-анализ. Теория и метод. Харьков: Гуманитарный центр. 352 с.

Хабермас Ю. 2001. Вовлечение другого. Очерки политической теории. СПб: Наука. 417 с.

BELUGINA Nadezhda Borisovna, postgraduate student at the Department of Political Science and Mass Communications, Financial University under the Government of the Russian Federation (49 Leningradsky Ave, GSP-3, Moscow, Russia, 125993; belugina.nb@gmail.com)

RYAZANOVA Liliya Vyacheslavovna, postgraduate student; Assistant at the Department of Political Science and Mass Communications, Financial University under the Government of the Russian Federation (49 Leningradsky Ave, GSP-3, Moscow, Russia, 125993; liliya_ryazanova@mail.ru)

\title{
POLITICAL DISCOURSE AS A COMMUNICATIVE PRACTICE OF CONSTRUCTING VIRTUAL POLITICAL REALITY
}

\begin{abstract}
On the base of a postmodern approach to understanding modernity, the authors identify the conditions of origin and the essence of a new phenomenon called virtual political reality and outline theoretical approaches to understanding of social and communicative practices of its construction. They emphasize that these phenomena, as well as discursive practices, are of a symbolic nature. Political discourse is considered as a communicative practice of creating semantic meanings of certain political phenomena and actions. The authors raise the issue of the mutual influence of discourse and social reality, considering the transformation of political discourse as a tool for constructing and changing virtual political reality.
\end{abstract}

Keywords: social practices, communicative practices, discourse, political discourse, virtual political reality 